\title{
In situ Occurrence, Prevalence and Dynamics of Parvilucifera Parasitoids during Recurrent Blooms of the Toxic Dinoflagellate Alexandrium minutum
}

\author{
Elisabet Alacid *, Albert Reñé, Jordi Camp and Esther Garcés \\ Departament de Biologia Marina i Oceanografia, Institut de Ciències del Mar, CSIC, Barcelona, Spain
}

\section{OPEN ACCESS}

Edited by:

Télesphore Sime-Ngando, Centre National de la Recherche

(CNRS), France

Reviewed by:

Catharina Alves-de-Souza, University of North Carolina at

Wilmington, United States

Lourdes Velo Suarez, French Research Institute for Exploitation of the Sea, France

*Correspondence: Elisabet Alacid alacid@icm.csic.es

Specialty section

This article was submitted to

Aquatic Microbiology

a section of the journal

Frontiers in Microbiology

Received: 06 May 2017 Accepted: 10 August 2017

Published: 31 August 2017

Citation:

Alacid E, Reñé A, Camp J and Garcés E (2017) In situ Occurrence,

Prevalence and Dynamics of Parvilucifera Parasitoids during

Recurrent Blooms of the Toxic Dinoflagellate Alexandrium minutum

Front. Microbiol. 8:1624.

doi: 10.3389/fmicb.2017.01624
Dinoflagellate blooms are natural phenomena that often occur in coastal areas, which in addition to their large number of nutrient-rich sites are characterized by highly restricted hydrodynamics within bays, marinas, enclosed beaches, and harbors. In these areas, massive proliferations of dinoflagellates have harmful effects on humans and the ecosystem. However, the high cell density reached during blooms make them vulnerable to parasitic infections. Under laboratory conditions parasitoids are able to exterminate an entire host population. In nature, Parvilucifera parasitoids infect the toxic dinoflagellate Alexandrium minutum during bloom conditions but their prevalence and impact remain unexplored. In this study, we evaluated the in situ occurrence, prevalence, and dynamics of Parvilucifera parasitoids during recurrent blooms of $A$. minutum in a confined site in the NW Mediterranean Sea as well as the contribution of parasitism to bloom termination. Parvilucifera parasitoids were recurrently detected from 2009 to 2013, during seasonal outbreaks of $A$. minutum. Parasitic infections in surface waters occurred after the abundance of $A$. minutum reached $10^{4}-10^{5}$ cells $L^{-1}$, suggesting a density threshold beyond which Parvilucifera transmission is enhanced and the number of infected cells increases. Moreover, host and parasitoid abundances were not in phase. Instead, there was a lag between maximum A. minutum and Parvilucifera densities, indicative of a delayed density-dependent response of the parasitoid to host abundances, similar to the temporal dynamics of predator-prey interactions. The highest parasitoid prevalence was reached after a peak in host abundance and coincided with the decay phase of the bloom, when a maximum of $38 \%$ of the $A$. minutum population was infected. According to our estimates, Parvilucifera infections accounted for $5-18 \%$ of the total observed A. minutum mortality, which suggested that the contribution of parasitism to bloom termination is similar to that of other biological factors, such as encystment and grazing.

Keywords: phytoplankton, plankton, protist, harmful algal blooms, Perkinsids, parasitism, infection flux

\section{INTRODUCTION}

In the last decades, toxic and harmful planktonic protist species have been the focus of scientific and public attention due to their environmental, economic, and public health impacts in coastal areas, which are of major importance for food production (Zingone and Enevoldsen, 2000). Around 200 species belonging to diverse groups of marine microalgae, including dinoflagellates, diatoms, 
pelagophytes, raphydophytes, and prymnesiophytes, have been identified as potentially harmful. Of these, about 90 species, mainly those of dinoflagellates, are potentially toxic (Zingone and Enevoldsen, 2000; Hallegraeff et al., 2003).

In the Mediterranean Sea, harmful algal blooms (HABs) commonly occur in areas with restricted hydrodynamics, such as bays, lagoons, harbors, beaches, and estuaries. These coastal proliferations are an emerging problem whose frequency has increased in response to the intensive urbanization and recreational use of the Mediterranean shoreline, which has resulted in nutrient-rich (semi-) confined areas with low turbulence levels. These areas constitute a unique environment that favors $\mathrm{HAB}$ formation by several planktonic protist species (Garcés and Camp, 2012). For example, the worldwide distributed Alexandrium minutum is responsible for outbreaks of paralytic shellfish poisoning in humans and for the high mortality of wild and cultured aquatic fauna (Anderson et al., 2012). It also forms recurrent blooms along the Catalan coast (NW Mediterranean Sea) (Vila et al., 2001, 2005; Bravo et al., 2008), which includes a large number of harbors and suffers from huge nutrient inputs from inland sources (Vila et al., 2001; Garcés et al., 2003; Bravo et al., 2008). However, many physical, chemical, and biological factors are involved in bloom development, persistence, and termination (Garcés and Camp, 2012). While most studies on HAB dynamics have focused on bottom-up factors, recent investigations have demonstrated a role for the top-down control exerted by biotic factors, such as parasitism and grazing (Coats et al., 1996; Johansson and Coats, 2002; Calbet et al., 2003; Chambouvet et al., 2008; Montagnes et al., 2008).

Parasitism on marine dinoflagellates by eukaryotic parasitoids is mainly due to members of the globally distributed genera Parvilucifera and Amoebophrya (Alveolata) (Park et al., 2004). The life cycle of these two parasitoids is, for the most part, similar. Infection begins when a free-living zoospore penetrates a host cell, where it develops into a trophocyte that enlarges while feeding on the host by completely digesting its cell contents. The trophocyte nucleus then divides, and transforms into a sporocyte to produce zoospores. Finally, the newly produced zoospores are released into the marine environment to find a new host (Jephcott et al., 2016). However, whereas after infection by Parvilucifera the host stops swimming and sinks immediately (Alacid et al., 2015), dinoflagellates parasitized by Amoebophrya continue swimming until late stages of the infection cycle (Park et al., 2002). Moreover, the sporangium of Parvilucifera is non-motile, unlike Amoebophrya, which forms a highly motile vermiform stage before spreading its zoospores (Fritz and Nass, 1992). Consistent with the features of their infection cycle, marine environmental molecular surveys have highlighted the high occurrence of Marine Alveolates Group II in the planktonic fraction (Guillou et al., 2008; de Vargas et al., 2015; Massana et al., 2015) pointing that Amoebophryidae species are much more abundant in the water column than in marine sediment. By contrast, Parvilucifera (Perkinsozoa) species are mostly detected in the marine sediment, with a much lower abundance in the water column (Chambouvet et al., 2014). Nonetheless, both groups of parasitoids infect and kill several genera of dinoflagellates, including noxious species, and their very strong virulence and high prevalence have been demonstrated in laboratory experiments and in the field (Coats and Park, 2002; Chambouvet et al., 2008). Thus, some authors have proposed the use of parasitoids as biological control agents for bloom mitigation (Norén et al., 1999; Erard-Le Denn et al., 2000). However, little is known about the specificity of these parasites or the potential unintended side effects on other dinoflagellate populations (Anderson, 2009). The mechanisms underlying host specificity are also not well understood, as intraand inter-species variability may depend on host phylogeny (Chambouvet et al., 2008) and/or the specific genetic features of the host and parasite. Both will determine the outcome of infection (Råberg et al., 2014; Turon et al., 2015; Alacid et al., 2016).

A few studies have addressed the interaction between parasites and their dinoflagellate hosts in the marine environment in order to assess the impact of parasitism in natural communities. Modeling studies have shown that, under certain conditions, parasitism may have a greater impact than grazing with respect to dinoflagellate population dynamics (Montagnes et al., 2008; Salomon and Stolte, 2010; Jordi et al., 2015). In the field, the prevalence of Amoebophyra parasites in dinoflagellate blooms is usually moderate to high (Coats et al., 1996; Chambouvet et al., 2008; Alves-de-Souza et al., 2012; Velo-Suárez et al., 2013) but under some conditions is the main cause of dinoflagellate mortality. In the case of Parvilucifera, although its high abundance has been correlated with a reduction in the relative abundance of $A$. minutum in short-lasting blooms (Blanquart et al., 2016), field studies on the prevalence of Parvilucifera infections, their impact on natural host populations, and the contribution of infection to bloom termination are lacking.

The main goals of this study were: (i) to determine the timing of Parvilucifera parasitoid occurrence in Arenys de Mar harbor, a confined area in the NW Mediterranean Sea; (ii) to assess hostparasitoid dynamics during a bloom of the toxic dinoflagellate A. minutum; and (iii) to quantify the impact and contribution of Parvilucifera spp. parasitism to bloom termination. The present work constitutes the first record of the impact of Parvilucifera parasitoids in the field.

\section{MATERIALS AND METHODS}

\section{Study Area}

Arenys de Mar harbor $\left(41^{\circ} 34.30^{\prime} \mathrm{N}\right.$ and $\left.2^{\circ} 32.40^{\prime} \mathrm{E}\right)$ is located on the coast of Catalonia (NE Spain), in the NW Mediterranean Sea (Figure 1). Fishing and leisure are the main human activities in the harbor. The harbor measures $0.4 \mathrm{~km}^{2}$, has a depth ranging from $1 \mathrm{~m}$ at confined sites to $6 \mathrm{~m}$ at the entrance, and receives large freshwater inputs rich in nutrients. Intense and recurrent A. minutum blooms between December and August have been recorded every year since 1999 (Vila et al., 2001; Garcés et al., 2004; Van Lenning et al., 2007; Bravo et al., 2008; Anglès et al., 2012). Their documentation was part of an extensive study of the ecology and bloom dynamics of A. minutum in this confined system (Garcés et al., 2004; Van Lenning et al., 2007; Anglès et al., 2010, 2012). In the present study, we assessed parasitic 


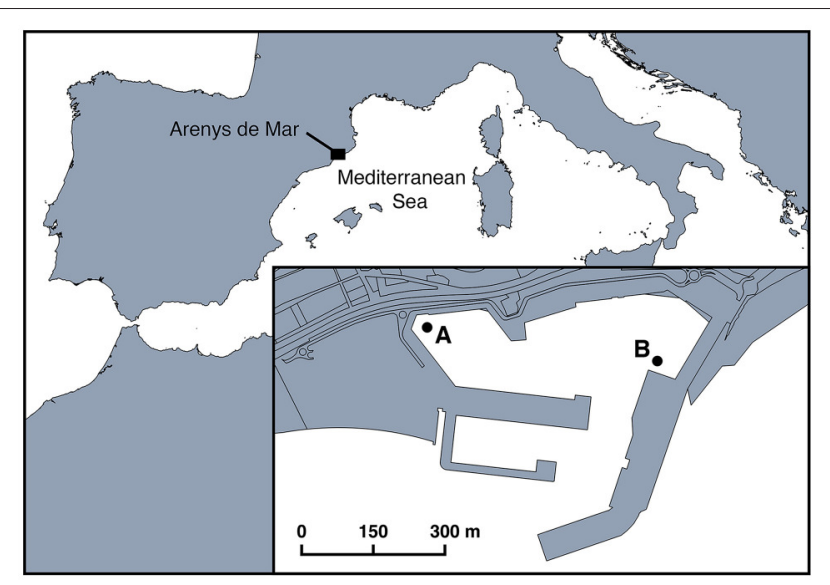

FIGURE 1 | Location of Arenys de Mar harbor in the northwest Mediterranean Sea. The two sampling stations ( $A$ and $B$ ) are shown in the inset.

occurrence and infection during A. minutum blooms at two sampling locations ( $\mathrm{A}$ and $\mathrm{B}$, Figure 1) where both vegetative cells and resting cysts reached their maximum abundances (Garcés et al., 2004; Anglès et al., 2010).

\section{Sampling and Determination of the Dinoflagellate Community}

Surface water samples were collected at $\sim 20 \mathrm{~cm}$ depth using a bucket. From 2009 to 2012, samples were collected from location A once a week between January and September, and once a fortnight from October to December. From January to April 2013, samples were collected at 12:00 GMT at locations A and B (Figure 1) every 5-7 days throughout the A. minutum bloom period. This sampling frequency is similar to that followed in previous studies assessing the changes in A. minutum abundances during recurrent blooms in the same harbor (Van Lenning et al., 2007; Anglès et al., 2012). To quantify the abundances of the main dinoflagellate species and the standing stock of dinoflagellate hosts, 10 - or 50 -mL subsamples were fixed in Lugol (2\%) and allowed to sediment in settling chambers for $24 \mathrm{~h}$. A Leica-Leitz DMIRB inverted microscope fitted with epifluorescence filters was then used to count at least 400 cells at 20x magnification. The confidence limit at the $95 \%$ significance level was $\pm 10 \%$, and the detection limit using the Utermöhl method 200 cells $\mathrm{L}^{-1}$ and 20 cells $\mathrm{L}^{-1}$ for the $10-\mathrm{mL}$ and $50-\mathrm{mL}$ samples, respectively (Edler and Elbrächter, 2010). A. minutum cells were evidenced by staining the thecal plates with Calcofluor white solution (Fritz and Triemer, 1985).

\section{Occurrence of Parvilucifera Parasitoids}

Parvilucifera occurrence, defined here as the detection of infected cells caused by Parvilucifera parasitoids in the samples, was assessed using data obtained from 2009 to 2012 in Arenys de Mar harbor. Thus, 6-L surface water samples were collected with the same sampling frequency used to obtain the plankton samples (Section Sampling and Determination of the Dinoflagellate Community), pre-filtered through a mesh with a $60-\mu \mathrm{m}$ pore size to discard possible predators, and then incubated for 4-5 days at room temperature $\left(20^{\circ} \mathrm{C}\right)$ under natural light. The sample was concentrated by the inverse filtration (10- $\mu \mathrm{m}$ pore size) of a 4-L water subsample and the presence of infected cells, defined as the detection of sporangia, was determined using light microscopy. The detection of $<10$ and $>10$ sporangia per concentrated sample was defined as the low and high presence of Parvilucifera spp., respectively. Samples with no sporangia were considered to be non-infected.

\section{Identification and Quantification of Parvilucifera Infections}

The impact of Parvilucifera infection during a bloom of A. minutum was quantified using only the data obtained during the bloom of 2013. Because the dinoflagellate host sinks after Parvilucifera infection (Alacid et al., 2015; Turon et al., 2015), two sediment traps were deployed to estimate both the number of infections caused by Parvilucifera and the flux of infected cells at locations A and B (Figure 1). Each trap consisted of a cylindrical collection vessel (height $33 \mathrm{~cm}$, diameter $10 \mathrm{~cm}$ ) moored $0.5 \mathrm{~m}$ from the bottom (the depth at each station was $2 \mathrm{~m}$ ). These traps were similar to those previously employed by Anglès et al. (2012) to quantify the encystment flux of a natural population of $A$. minutum. Under culture conditions, the $P$. sinerae infection cycle in $A$. minutum lasts 3-4 days at a water temperature of $20^{\circ} \mathrm{C}$ (Alacid et al., 2015) and 5-6 days at a water temperature of $15^{\circ} \mathrm{C}$ (Råberg et al., 2014). The generation time of Parvilucifera at $14^{\circ} \mathrm{C}$ (average water temperature during the sampling period) was 6-7 days and was estimated using the Q10 temperature corrector (see Section Parasitoid Infection Flux and Prevalence). Based on this estimation, samples were collected from the sediment traps with a frequency of 5-7 days throughout the 2013 bloom period (from January to April). The same sampling frequency was used for host sampling (surface water samples). All settled material was fixed with formaldehyde ( $1 \%$ final concentration) and stored for $1 \mathrm{~h}$ in the dark at $4^{\circ} \mathrm{C}$. Subsamples $(100 \mathrm{~mL})$ were filtered through a mesh of $10-\mu \mathrm{m}$, rinsed with $250 \mathrm{~mL}$ of autoclaved seawater to remove small sediment particles, and then concentrated in $10 \mathrm{~mL}$ of autoclaved seawater in 15-mL Falcon tubes (BD Falcon). From the latter, 1-5 mL were filtered onto $0.8-\mu \mathrm{m}$ polycarbonate filters (25$\mathrm{mm}$ diameter) using a vacuum pump at 150 mbar at room temperature. Cellulose-acetate support filters were used during filtration to promote the homogeneous distribution of the cells. The filters were cut into pieces with a razor blade, dipped in lowgelling-point agarose $(0.1 \%)$ to avoid cell loss, and then dried face-down on Parafilm. The filter sections were then mounted on a microscope slide, placed in a mixture consisting of four parts Citifluor and one part Vecta Shield containing $4^{\prime}-6^{\prime}$-diamidino2-phelylindole (DAPI; final concentration $1 \mu \mathrm{g} \mathrm{mL} \mathrm{mL}^{-1}$ ), and stored at $4^{\circ} \mathrm{C}$ in the dark until they were observed at $400 \mathrm{x}$ using an Olympus BX61 epifluorescence microscope. Ultraviolet excitation allowed the detection of the DAPI signal of the host nuclei and of the parasitoid nuclei in the sporangium stage. Bluelight excitation was used to detect the green autofluorescence of Parvilucifera parasitoids in the sporangium stage vs. the red 
autofluorescence of host chlorophyll. Parvilucifera infections were confirmed within the whole dinoflagellate community. Parasitoid sporangia were classified into morphotypes based on the size and disposition of the nuclei inside the sporangia and on sporangial morphology. Micrographs were taken using an Olympus DP72 camera (Olympus America Inc.) attached to the microscope. Parvilucifera sporangia were counted in 3-4 transects $\left(\sim 11 \times 0.5 \mathrm{~mm}^{2}\right.$ each) across the filter piece to analyze a representative area of the whole filter. The detection limit under these conditions was $\sim 75$ cells $\mathrm{L}^{-1}$.

\section{Parasitoid Infection Flux and Prevalence}

The abundance of total parasitoid infections in the sediment traps (data from 2013) was used to determine the daily infection fluxes (infected cells $/ \mathrm{m}^{2} \mathrm{day}^{-1}$ ) during the bloom. Infection fluxes were obtained by multiplying the abundance of infected cells (infected cells $\left.\mathrm{L}^{-1}\right)$ by the trap volume $\left(\mathrm{L}^{-1}\right)$ and dividing first by the trap aperture $\left(\mathrm{cm}^{2}\right)$ and then by the corresponding time interval (days) between the deployment and removal of the traps. To estimate parasitoid prevalence within the host population, the number of infected cells accumulated during the deployment of the sediment traps was divided by the corresponding duration of their deployment to obtain the number of infected cells per day. Parasitoid prevalence within an A. minutum population was calculated as the number of infected cells per day as a percentage of the total $A$. minutum population according to:

Prevalence $=\frac{\text { Infected cells } \cdot \text { day }^{-1}}{\text { A.minutum standing stock }+ \text { infected cells } \cdot \text { day }^{-1}} \times 100$

Prevalence was similarly determined with respect to the total dinoflagellate community:

Prevalence $=\frac{\text { Infected cells } \cdot \text { day }^{-1}}{\text { Dinoflagellate standing stock }+ \text { infected cells } \cdot \text { day }^{-1}} \times 100$

This was done to compare the effect of these parasitoids on the blooming host population and on the total dinoflagellate community, since under laboratory conditions Parvilucifera species infect a wide range of dinoflagellate species (Figueroa et al., 2008; Garcés et al., 2013a; Lepelletier et al., 2014), reflecting their large number of potential hosts in the field.

\section{Host Mortality Due to Parasitism}

Host mortality induced by Parvilucifera parasitoids, i.e., the percentage of hosts killed per day, was estimated as described by Coats and Bockstahler (1994) for Amoebophrya parasitoids:

$$
\text { Host mortality }=\frac{\left[\frac{\text { Prevalence }}{\mathrm{gt}}\right]}{100}
$$

where gt is the generation time of Parvilucifera from the sporangium stage until zoospore release. Here, this value was estimated to be 1.6 days, based on the gt determined for Parvilucifera sinerae at $20^{\circ} \mathrm{C}$ by Alacid et al. (2015) and at $15^{\circ} \mathrm{C}$ by Råberg et al. (2014) under culture conditions (3.5 and 5.5 days, respectively). The gt was then converted to per day rates of 0.28 and 0.18 day $^{-1}$, respectively. The temperature was corrected by applying the $\mathrm{Q}_{10}$ temperature coefficient of 2.5 units, considering the average ambient temperature $\left(14^{\circ} \mathrm{C}\right)$ recorded during the A. minutum bloom in 2013 , and the $\sim 24$ h needed for sporangia to release their zoospores at $20^{\circ} \mathrm{C}$ (Turon et al., 2015). The $\mathrm{Q}_{10}$ is a measure of the rate of change of a biological system as a function of an increase in temperature of $10^{\circ} \mathrm{C}$. It is estimated by the equation:

$$
Q_{10}=\left(\frac{R_{2}}{R_{1}}\right)^{\left(\frac{10}{T_{2}-T_{1}}\right)}
$$

where $R$ is the per day rate (of change) at a specific temperature $(T)$; i.e., $R_{1}$ is the per day rate at temperature $T_{1}$, and $R_{2}$ the per day rate at temperature $T_{2}$.

To estimate the contribution of parasitoid-induced mortality to bloom termination, the in situ net mortality rate of $A$. minutum was calculated as the decrease in host cell abundance during the decay phase, in this case from March 26th to April 23rd, following the method of Guillard (1973):

$$
\mu=\frac{1}{\left(t_{2}-t_{1}\right)} \ln \frac{N_{2}}{N_{1}}
$$

where $\mu$ is the mortality rate in days ${ }^{-1}$ and $N_{2}$ and $N_{1}$ are the cell abundances at $t_{2}$ and $t_{1}$, respectively. The contribution of parasitoid infection to bloom termination was estimated based on the mean percentage of A. minutum and the mortality caused by Parvilucifera spp. during the decaying phase of the bloom.

\section{RESULTS}

\section{Seasonal Patterns of Alexandrium minutum Blooms and Parasitoid Occurrence during 4 Consecutive Years}

Between 2009 and 2012, dinoflagellates caused annually recurrent high-biomass blooms at location A. Between June 2010 and 2011, host concentrations at this site were as high as $10^{7}$ cells $\mathrm{L}^{-1}$ (Figure 2). A recurrent peak in A. minutum abundance was consistently detected in winter (late February-beginning of March) and caused high-biomass blooms. Other peaks in the abundance of this species occurred in June and July, although the abundances were lower than those reached in winter.

During the sampling period, Parvilucifera parasitoids were detected every year, from 2009 to 2012, when A. minutum reached bloom abundances as high as $10^{4}-10^{5}$ cells $\mathrm{L}^{-1}$ (Figure 2). Parasitic infections in the surface waters were first detected when $A$. minutum abundances were $\sim 10^{5}$ cells $\mathrm{L}^{-1}$ (blue horizontal band in Figure 2). Thereafter, parasite occurrence continued, even when $A$. minutum abundance declined to $10^{2}$ cells $\mathrm{L}^{-1}$. In general, total Parvilucifera spp. occurrences lasted 1-2 months, depending on the duration of the specific bloom. In the first weeks of the bloom, the parasitoids had a low-level presence, but when high host abundances were maintained over 2-3 weeks their strong presence was observed, including during 


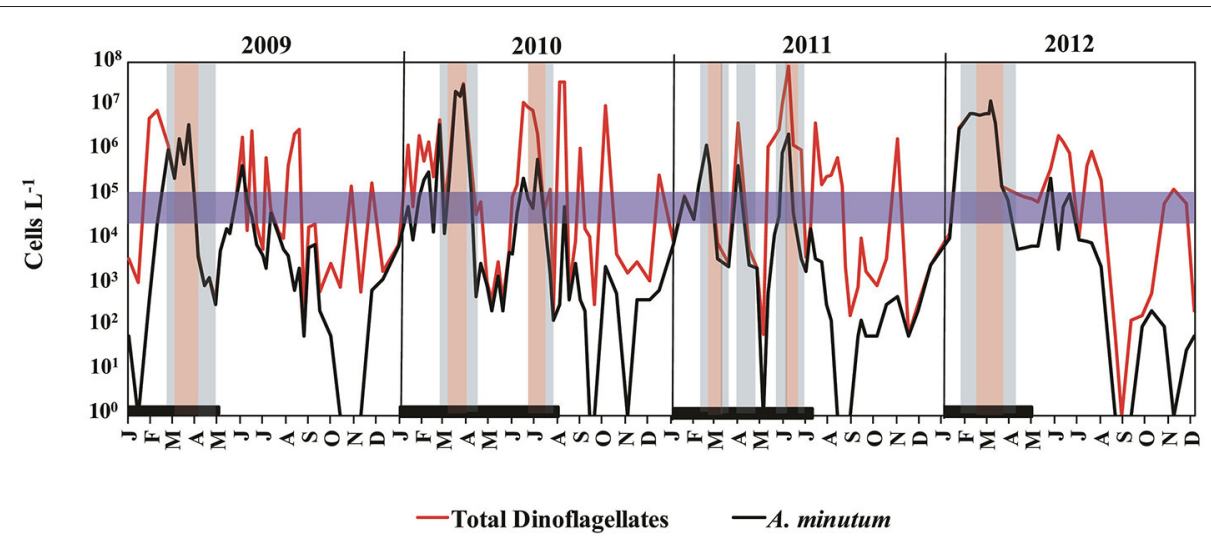

FIGURE 2 | Seasonal patterns of total dinoflagellates (in red), Alexandrium minutum abundance (in black), and parasitoid occurrence during a 4-year period (2009-2012) in Arenys de Mar harbor. The thick black line along the bottom indicates the sampling period for Parvilucifera parasitoids. The blue horizontal band is the concentration threshold $\left(10^{4}-10^{5}\right.$ cells $\left.L^{-1}\right)$ of $A$. minutum needed to enhance Parvilucifera spp. infection. Blue and red shading indicates the low and high presence of Parvilucifera spp., respectively.

the initial phase of the bloom decrease. Finally, at an advanced phase of bloom termination, the parasitoids again reached low abundances, which continued to decline until Parvilucifera spp. were no longer detected in the incubated surface water samples.

\section{Dinoflagellate Abundance and Composition, Infection Flux, and Parasitoid Prevalence during the $\mathbf{2 0 1 3}$ Winter Bloom}

During the sampling period, from February to April 2013 and at both sampling sites, total dinoflagellate abundance increased two-fold from January to late March, reaching a peak on March 26th of up to $10^{6}$ cells $\mathrm{L}^{-1}$ and decreasing to as low as $10^{3}$ cells $\mathrm{L}^{-1}$ in early April (Figures 3A,D). Total dinoflagellate abundance coincided with the fluctuations of A. minutum, which was the dominant species during almost the whole sampling period. The bloom of this species lasted 2 months, from early February to early April. During this period, the dinoflagellate species composition changed depending on the bloom phase. Thus, initially, the dinoflagellate community was more diverse but composed principally of A. minutum, Prorocentrum micans, and Scrippsiella spp. Thereafter, A. minutum grew exponentially, with a several-fold increase in its abundance until it dominated the dinoflagellate community (up to $90 \%$ of the species contribution). Exponential growth stopped when A. minutum reached a peak abundance of up to $10^{5}$ cells $\mathrm{L}^{-1}$ at location $\mathrm{A}$ and $10^{6}$ cells $\mathrm{L}^{-1}$ at location $\mathrm{B}$. Abundances of $10^{5}$ cells $\mathrm{L}^{-1}$ were sustained for 10 days at location A and for 15 days at location B; in the latter, abundances increased to as high as $10^{6}$ cells $\mathrm{L}^{-1}$ during a 1-week period. After the peak of the bloom, during the decline in A. minutum, the dinoflagellate community again became more diverse, with an increased dominance of Scrippsiella spp. and P. micans, whereas A. minutum abundances reached their lowest values.

Parvilucifera spp. infections were restricted to dinoflagellates, but from a total of 17 recorded dinoflagellate taxa (data not shown) only three of them were infected: A. minutum, Scrippsiella spp., and P. micans. However, while infected cells of A. minutum were observed throughout the bloom at both locations, infection of only a few cells of Scrippsiella spp. was observed at location A on only two sampling dates, February 19th and March 4th, and of only a single infected cell of P. micans on March 4th, also at location A. The detection of infected Scrippsiella spp. cells coincided with the maximum abundance of this dinoflagellate $\left(10^{4}\right.$ cells $\left.\mathrm{L}^{-1}\right)$ and with a decrease of A. minutum.

The infection flux caused by Parvilucifera spp. parasites followed dynamics similar to those of their hosts but with a oneperiod phase lag between A. minutum and Parvilucifera densities (Figures 3B,E). The number of infected cells increased gradually at both locations, albeit with a delay, and pointed to a densitydependent response to the increase in host cells during the bloom period. At location A (Figure 3B), during the initial phase of the bloom, host cell abundance in the water column was relatively stable, with values of $\sim 10^{4}$ cells $\mathrm{L}^{-1}$, until March 11th. During this period, the infection flux was also stable, with Parvilucifera spp. parasitoids infecting $\sim 10^{3}$ cells $/ \mathrm{m}^{2}$ day $^{-1}$. After March 11th, corresponding to the exponential growth phase of the bloom, the infection flux increased one-fold, reaching a maximum on April $3 \mathrm{rd}$ of up to $10^{4}$ infected cells $/ \mathrm{m}^{2}$ day ${ }^{-1}$. This maximum occurred immediately after the peak in the A. minutum concentration $\left(10^{5}\right.$ cells $\left.\mathrm{L}^{-1}\right)$ on March $26 \mathrm{th}$. After the peak, the abundance of A. minutum gradually decreased, to $10^{3}$ cells $\mathrm{L}^{-1}$, although the total dinoflagellate concentration was $10^{4}$ cells $\mathrm{L}^{-1}$. The slight decrease in the infection flux coincided with the decrease in A. minutum abundance. At location B (Figure 3E), the initial phase of the bloom was much shorter, with the exponential phase starting on February 11th. The infection flux during this initial period was about $10^{3}$ cells $/ \mathrm{m}^{2}$ day $^{-1}$, and it slightly increased until a maximum of $10^{4}$ cells $/ \mathrm{m}^{2}$ day ${ }^{-1}$ was reached, on April 3 rd. The A. minutum standing stock of vegetative cells at location $B$ was one order of magnitude higher than that at location A, although the maximum infection flux $\left(10^{4}\right.$ cells $\left./ \mathrm{m}^{2} \mathrm{day}^{-1}\right)$, 
A

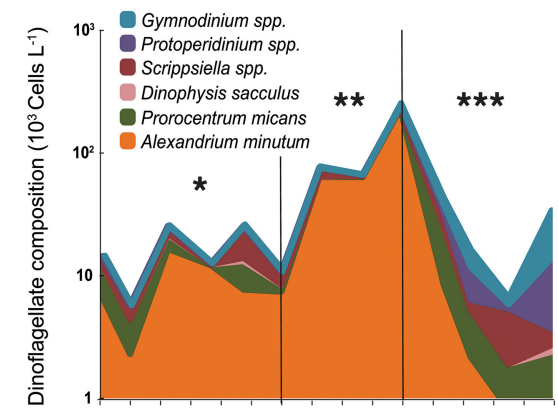

B

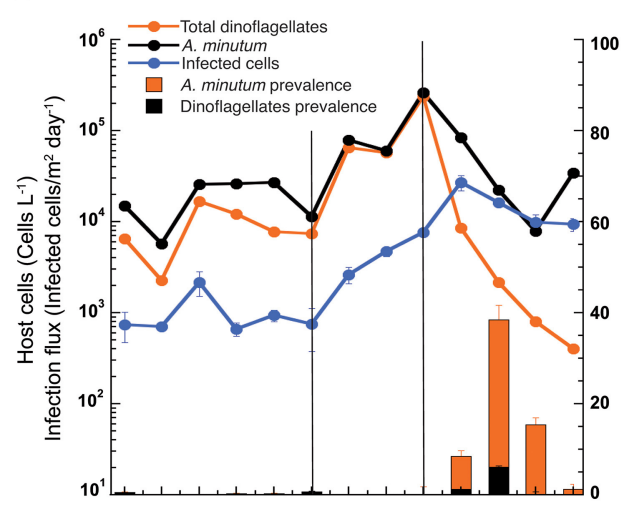

C

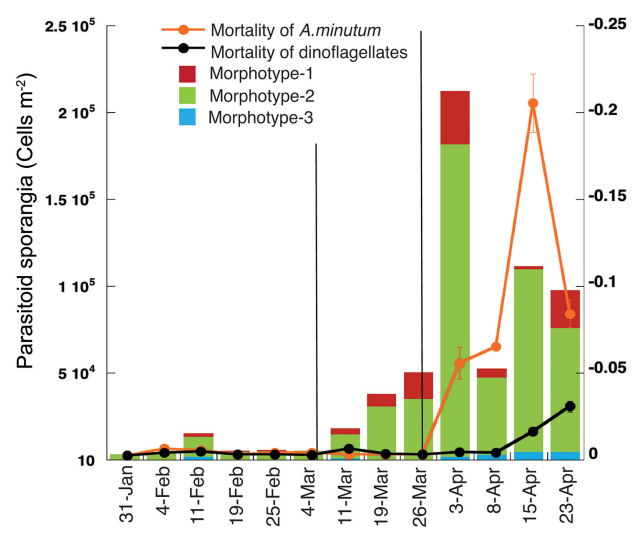

D

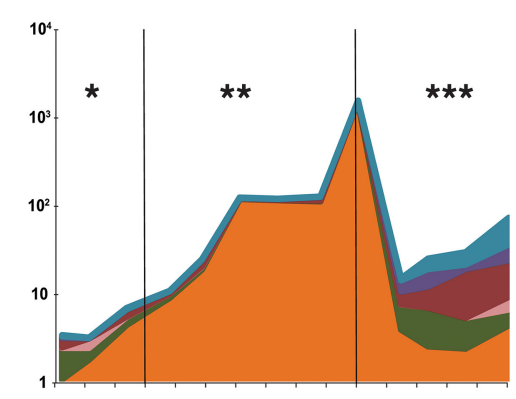

E

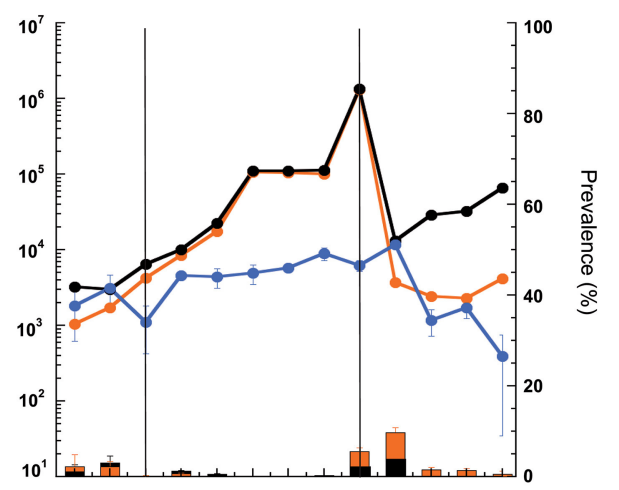

F

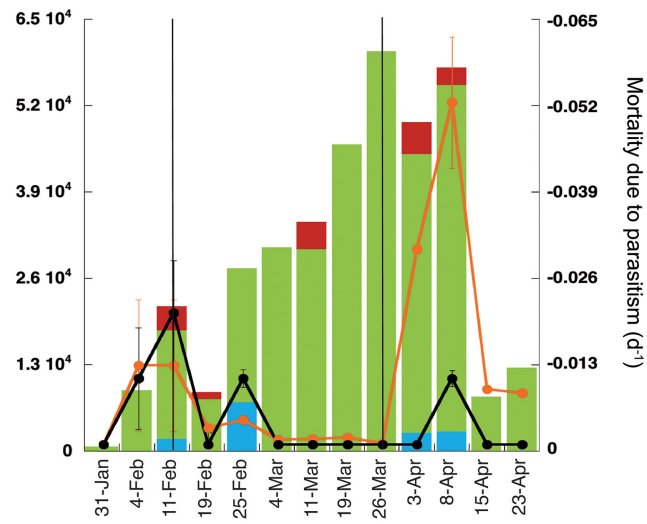

FIGURE 3 | Host-parasitoid dynamics during the winter bloom (from February to April 2013) in Arenys de Mar harbor at locations A (A-C) and B (D-F). (A,D) Major species composition and contribution to the total dinoflagellate abundance. Note the log scale. (B,E) Infection dynamics and prevalence during the bloom. The left-y axis is the infection flux (infected cells $/ \mathrm{m}^{2}$ day ${ }^{-1}$ ) and host cell abundance (cells $\mathrm{L}^{-1}$ ) of the standing stock. The right- $y$ axis is the prevalence (\% of infected cells of the population). (C,F) The left-y axis is the contribution of the different Parvilucifera spp. sporangia morphotypes to the total parasitoid density (cells $\mathrm{m}^{-2}$ ), and the right-y axis host mortality $\left(\right.$ day $\left.^{-1}\right)$ caused by the parasitic infection. Asterisks indicate the bloom phase: $\left(^{\star}\right)$ initial phase, $\left({ }^{\star \star}\right)$ exponential growth, and $\left(^{(\star \star}\right)$ bloom decrease.

achieved immediately after the peak of the bloom, was the same at the two sites. Following the dramatic decline of the A. minutum population, by more than two orders of magnitude, the infection flux declined by one order of magnitude.

The parasitoid prevalences at locations $\mathrm{A}$ and $\mathrm{B}$ followed a similar pattern (Figures 3B,E), with very low percentages $(0-5 \%)$ of the host population infected either before peak bloom development during the initial phase or during the exponential growth phase. The percentage of infected hosts increased after the bloom peak, with a mean of $18 \%$ at location $\mathrm{A}$ and $6 \%$ at location $\mathrm{B}$ and coinciding at both sites with the rapid decrease in A. minutum. Maximum prevalences, reached between April 3 rd and 15th, were much higher at location $\mathrm{A}$ than at location $\mathrm{B}$, evidenced by maximum values of 38 and $12 \%$ of the A. minutum population, respectively. The impact of the parasite prevalence on the total dinoflagellate community was very low at both locations 
over the entire course of the bloom, with a maximum of $7 \%$ at location $\mathrm{A}$ and $4 \%$ at location B.

\section{Parasitoid Sporangial Abundance and Dinoflagellate Mortality Due to Parasitic Infection}

Total sporangial abundance followed the same dynamics as the A. minutum density, with a higher abundance occurring close to the A. minutum (host) peak and then diminishing as the bloom declined (Figures 3C,F). At the initial phase of the bloom, sporangial abundance was slightly lower than during the exponential growth phase, ranging from $10^{2}$ to $10^{4}$ cells $\mathrm{m}^{-2}$ in the sediment traps. The mean sporangial abundance was $2.5 \cdot 10^{3}$ cells $\mathrm{m}^{-2}$ at location $\mathrm{A}$ and $4.5 \cdot 10^{3}$ cells $\mathrm{m}^{-2}$ at location $\mathrm{B}$. After the maximum of $A$. minutum abundance, the sporangial density at location A (Figure 3C) increased by one order of magnitude, reaching $2 \cdot 10^{5}$ cells $\mathrm{m}^{-2}$. The concentration of sporangia decreased only marginally thereafter and was thus maintained at $\sim 5 \cdot 10^{4}-10^{5}$ cells $\mathrm{m}^{-2}$ during the decay phase of the bloom. At location B (Figure 3F), the maximum sporangial density in the traps was $6 \cdot 10^{4}$ cells $\mathrm{m}^{-2}$, coinciding with the peak in A. minutum abundance but then continuing for 2 weeks. This density was one order of magnitude lower than that in location A, although the host cell concentration was higher. Sporangial abundance underwent a sharp decrease when the A. minutum abundance declined to $<10^{3}$ cells $\mathrm{L}^{-1}$.
Three different Parvilucifera sporangial morphologies were identified in samples from sediment traps placed during the A. minutum bloom. They could be distinguished based on their nuclear distribution and sporangial morphology (Figure 4). While we were unable to attribute morphotype-1 to any of the five existent Parvilucifera species described to date, morphotype2 was linked to $P$. sinerae, based on the morphological similarities of the sporangia, determined under optical and epifluorescence microscopy, to those described in Alacid et al. (2015). Morphotype-3 was likely related to Parvilucifera prorocentri, due to its pear-shaped sporangial morphology (Leander and Hoppenrath, 2008). Morphotype-1 was the second most abundant parasitoid, with a density ranging from $10^{2}$ to $10^{4}$ cells $\mathrm{m}^{-2}$. This morphotype was present in almost all samples obtained throughout the bloom. Morphotype- 2 was the most abundant in the sediment traps and was the cause of most of the infections. In addition, it was dominant during the whole bloom and at both locations (green bar, Figures 3C,F). At location A (Figure 3C), the density of morphotype-2 ranged from $10^{3}$ to $10^{5}$ cells $\mathrm{m}^{-2}$. Morphotype- 3 was only detected sporadically, before the peak of the bloom, and at low concentrations $\left(10^{2}\right.$ cells $\left.\mathrm{m}^{-2}\right)$. It was recurrently present at the late phase of the bloom, from April 3rd to $23 \mathrm{rd}$ and at a higher concentration $\left(\sim 10^{3}\right.$ cells $\mathrm{m}^{-2}$ ). At location B (Figure $3 \mathbf{F}$ ), the density of morphotype2 was stable throughout the bloom period at $\sim 10^{4}$ cells $\mathrm{m}^{-2}$, with the lowest abundances at the very early phase and again at the late phase. The other two morphotypes were intermittently
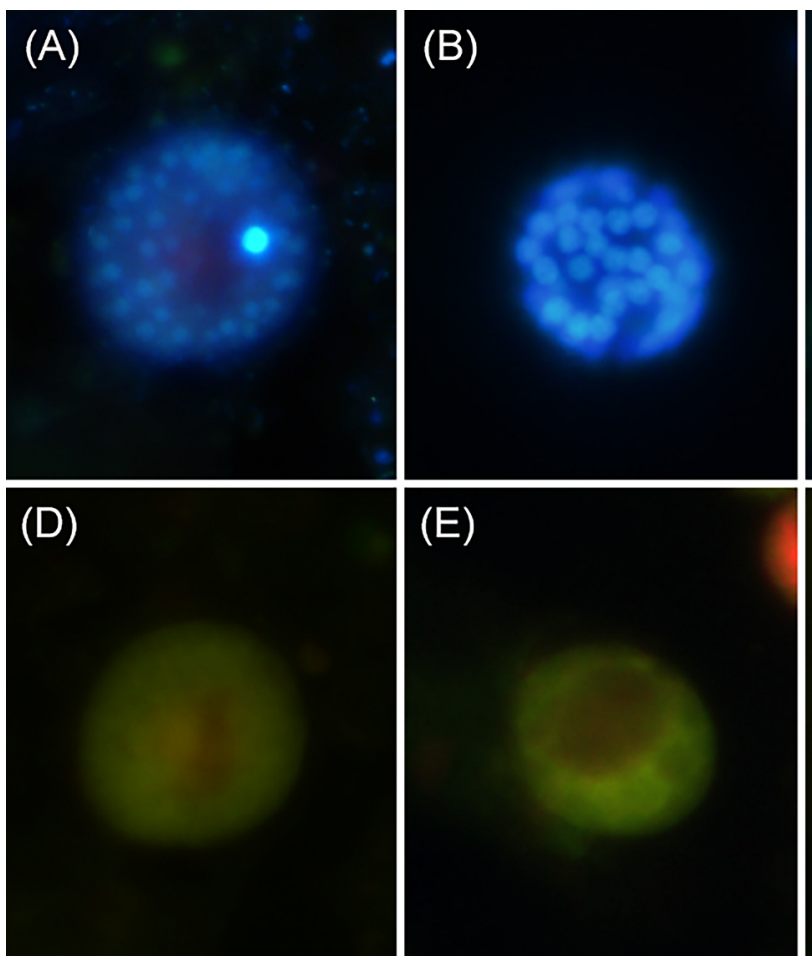
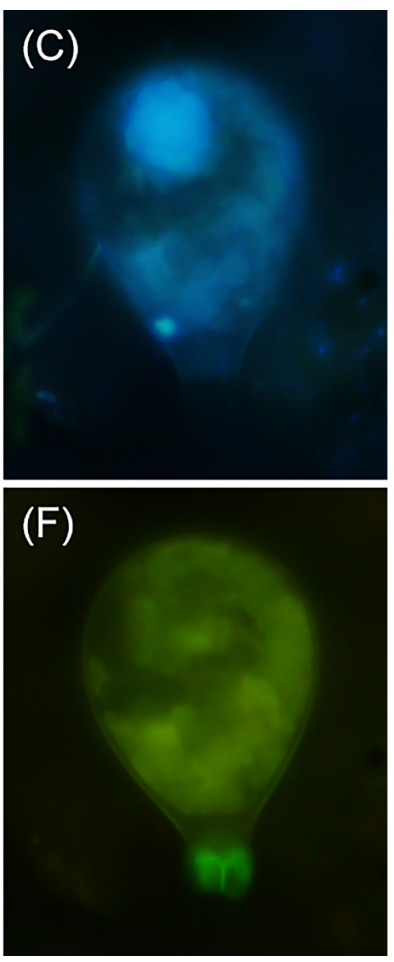

FIGURE 4 | Parvilucifera spp. morphotypes identified in the sediment traps during the A. minutum winter bloom of 2013. (A-C) Sporangia and their DAPI-stained nucleus/nuclei. (D-F) The green autofluorescence of the sporangia under blue light excitation. (A,D) Morphotype-1; (B,E) morphotype-2; (C,F) morphotype-3. 
detected over the course of the bloom at abundances of $\sim 10^{3}$ cells $\mathrm{m}^{-2}$.

The highest A. minutum mortalities due to Parvilucifera parasitism occurred after the maximum parasite density (Figures 3C,F) and after the peak host concentration, coinciding with the bloom decay phase at both locations. Before the peaks of host and parasite abundance, Parvilucifera spp. killed an average of $0.2 \%\left(-0.002 \mathrm{day}^{-1}\right)$ and $0.7 \%\left(-0.007 \mathrm{day}^{-1}\right)$ of the host population per day at locations $\mathrm{A}$ and $\mathrm{B}$, respectively. Host mortality increased after the peak of Parvilucifera abundance, with the parasites killing, on average, $10 \%\left(-0.1\right.$ day $\left.^{-1}\right)$ of the A. minutum population every day. The estimated mortality rate during the termination phase of the bloom was lower at location $\mathrm{B}$ than at location A, with $2.3 \%\left(-0.023 \mathrm{day}^{-1}\right)$ of the host population killed. Maximum host mortalities of $-0.21 \mathrm{day}^{-1}$ and $-0.053 \mathrm{day}^{-1}$ at locations $\mathrm{A}$ and $\mathrm{B}$, respectively, were reached immediately after the maximum in Parvilucifera abundances. On average, at location A, Parvilucifera parasites killed 3.4\% of the A. minutum population $\left(-0.034 \mathrm{day}^{-1}\right)$ each day. Considering a decrease of -0.2 day $^{-1}$ in $A$. minutum abundance at the end of the bloom, parasitism due to Parvilucifera was estimated to account for $18 \%$ of the total A. minutum mortality at location A between March 26th and April 23rd, and for 5\% at location B during the same period.

\section{DISCUSSION}

\section{Coupled Host-Parasitoid Occurrence and Dynamics in the Field}

A. minutum is a potentially toxic dinoflagellate and a common species in the Mediterranean. In the NW Mediterranean, it is present at low abundances throughout the year in the studied location, but once or twice per year, mainly in winter, it proliferates to form high-biomass blooms. As demonstrated in this study, Parvilucifera infections accompany these outbreaks, becoming prominent when the dinoflagellate community is almost mono-specific (>90\%) for A. minutum. Algal blooms, with their low species diversity and very high abundances (Maso and Garcés, 2006; Sunda et al., 2006; Egerton et al., 2014), are temporary states of the dinoflagellate community. According to the diversity-disease hypothesis of Elton (1958), these communities are vulnerable to parasitic infection and transmission. Elton observed that infectious disease outbreaks due to parasitism most often involve dense, human-simplified communities, such as cultivated land, or, using the example of more recent cultivation systems, marine farmed species (Lafferty et al., 2015). A. minutum blooms reported here, with their low species diversity and high cell densities (Figures 3A,D), resemble these systems and thus also support parasitic occurrences. The high host densities reached during dinoflagellate blooms will increase the likelihood of encounter between parasitoids and their hosts (Dobson, 1990), thereby increasing infection transmission and parasitoid load to the system. By contrast, in the absence of a bloom, the low host densities reduce the probability of encounter with susceptible hosts and the infection accordingly subsides.
Infections by Parvilucifera parasites at the surface waters were detected only after a peak in A. minutum abundance, suggesting the existence of a density threshold that promotes the transmission and spread of Parvilucifera infections within the host population. In this study, the minimum $A$. minutum concentration needed to enhance parasitoid infection was $\sim 10^{4}$ $10^{5}$ host cells $\mathrm{L}^{-1}$. Blanquart et al. (2016) followed $A$. minutum and Parvilucifera dynamics in two estuaries in France. Whereas, qPCR failed to detect the parasite in the water column at the beginning of the blooms, Parvilucifera parasitoids were detected when the density of $A$. minutum, the major contributor to the dinoflagellate community, reached $10^{5}$ cells $\mathrm{L}^{-1}$. The need for a minimum host density that enhances parasite transmission and furthers infections demonstrates a direct host density dependence, in agreement with another densitydependent response described by Garcés et al. (2013b) for the same host-parasitoid system: sporangial activation from a dormant stage. In that process, higher host densities release high concentrations of dimethylsulfide (DMS), which through chemical signaling activates a higher proportion of sporangia containing dormant infective zoospores. DMS “informs" the parasitoid of the presence of a high host abundance in the environment and thus facilitates infection and transmission within the dense host population.

Moreover, as the bloom advances, the increasing host density provokes an increase in the number of infections, thereby enlarging the Parvilucifera population. Interestingly, parasitoid abundance was not in phase with the abundance of A. minutum; rather, Parvilucifera spp. followed a time-delay response to the temporal fluctuations of its blooming hosts, similar to the temporal dynamics of predator-prey interactions. The flux of infected cells was characterized by a lag in host abundance such that infection peaked after the host cells had achieved their maximum density. Then, the parasitoid population in the water column decreased as the bloom declined. This finding is consistent with a direct negative density dependence such as also occurs for predator-prey systems (Begon et al., 2005). Comparable dynamics were also observed in the above-described study by Blanquart et al. (2016) and for parasitoids belonging to the Amoebophryidae during blooms of several dinoflagellate species in different locations (Coats and Park, 2002; Chambouvet et al., 2008; Alves-de-Souza et al., 2012). Both Amoebophryidae and Parvilucifera grow inside the host, killing it as an obligate part of their life-cycles. Therefore, the ecology and population dynamics of parasitoids lie somewhere in between those of predators and true infectious parasites, such as bacteria and protozoa (Hassell, 2000).

The parasitoid community during the bloom could be classified into three Parvilucifera morphotypes. The dominance and A. minutum-coupled dynamics of morphotype-2 (P. sinerae) during the bloom agreed with the results reported by Turon et al. (2015), who, based on the $18 \mathrm{~S}$ rDNA gene, determined that all Parvilucifera isolates from A. minutum blooms from the Atlantic and Mediterranean coast (most of them in Arenys de Mar harbor) were P. sinerae. Although in host-range laboratory experiments using monospecific cultures Parvilucifera species were shown to be generalist pathogens of dinoflagellates (Norén 
et al., 2001; Garcés et al., 2013a; Lepelletier et al., 2014), the persistent occurrence and dominance of $P$. sinerae during A. minutum natural blooms indicated a greater specialization of the parasitoid. This field specificity agrees with the preference of $P$. sinerae for A. minutum demonstrated in an artificial mixed community (Alacid et al., 2016). A strong in situ specialization is known for Amoebophrya parasitoids. Chambouvet et al. (2008) reported the coexistence of several Amoebophrya clades, with consecutive blooms caused by a different dinoflagellate species and followed by an increase in the abundance of a specific parasitoid clade. Whether Parvilucifera species are characterized by the same dynamics as Amoebophrya requires further study of the in situ specificity of these parasitoids. The results will reveal details regarding their species- and community-level dynamics and the co-evolution of their hosts.

The host density threshold required to trigger an increase of Parvilucifera infections and the delayed density-dependent response of the parasitoid to host abundances have relevant sampling implications. Thus, a specific parasitoid will be significantly abundant in the water column only if its host is also abundant. If at the time of sampling, the host is absent or its density is below the threshold for infection, the parasitoid will not be detected. Moreover, studies of the ecology of Parvilucifera must also take into account the meroplanktonic life cycle of these parasitoids, which have a documented benthic stage (i.e., the sporangia) and thus alternate between the water column and the sediment. Taken together, our results explain why, in discrete environmental samples, Parvilucifera parasitoids are more abundant and active in the marine sediment (Chambouvet et al., 2014) than in the water column, where they have been scarcely detected (de Vargas et al., 2015; Lepère et al., 2015; Massana et al., 2015).

\section{Parasitism and Bloom Termination}

Historically, studies on why dinoflagellate blooms decline only considered environmental and physico-chemical factors (Margalef, 1978). However, recent studies have identified biological interactions, such as parasitism and grazing, as important factors in bloom dynamics, since the nature of those interactions affect host population densities (Coats et al., 1996; Johansson and Coats, 2002; Calbet et al., 2003; Montagnes et al., 2008; Velo-Suárez et al., 2013; Alves-de-Souza et al., 2015).

To date, the impact of eukaryotic parasitism in dinoflagellate blooms has been studied only in Amoebophrya whereas that of the genus Parvilucifera in natural populations is unknown, as only data from laboratory experiments are available. The estimated prevalence of Parvilucifera during the A. minutum natural bloom, as determined in this study, reached a maximum of $38 \%$, which is much lower than demonstrated in laboratory experiments (>90\% for clonal strains) (Alacid et al., 2015, 2016). These differences can be attributed to the many factors in the field that are absent from laboratory conditions, including those that cause direct parasitoid losses, such as grazing on the freeliving infective zoospores (Johansson and Coats, 2002), and those that reduce infection success, including dinoflagellate vertical migration (Coats and Bockstahler, 1994), host and parasite genetic diversity (Blanquart et al., 2016), and abiotic conditions such as turbulence (Llaveria et al., 2010).
Although, locations A and B were in the same harbor, they differed remarkably with respect to parasitoid prevalence and host mortality, thus demonstrating the high spatial heterogeneity and patchiness of parasitism as also reported for dinoflagellate vegetative cells during blooms (Garcés et al., 2004). Since host density appears to be fundamental to infection and transmission, a higher infection level was expected at location $\mathrm{B}$, where A. minutum abundance was one order of magnitude higher, than at location A. However, parasitoid prevalence and host mortality were higher at the latter location, which points to the role played by the differences in the physical and biological factors of the two locations. Location B is situated close to the entrance of the harbor and is probably more exposed and its waters more turbulent. Turbulence is an important factor that reduces parasite infectivity (Llaveria et al., 2010). Conversely, location $\mathrm{A}$ is more protected such that its low hydrodynamics and confinement promoted rates of infection and prevalences similar to those of laboratory conditions. Moreover, mean salinity values during the sampling period were much lower in location $\mathrm{A}$ $(34.2 \%$ ) than in location B $(37.8 \%$ ). Low salinity levels produce the activation of $P$. sinerae zoospores inside the sporangia and their subsequent release to the environment (Figueroa et al., 2008), which also may explain the higher levels of infection reached in location A. Further studies assessing the contributions of abiotic factors to the success of parasitic infection will allow a better understanding of the variable rates of infection observed in natural blooms. As previously suggested for differences in $P$. infectans infectivity along the Swedish coast (Johansson et al., 2006), differences in the community composition of predators may influence infection rates in the field, as demonstrated for a community rich in grazers in preventing high infection levels (Johansson and Coats, 2002; Kagami et al., 2004; Alvesde-Souza et al., 2015). Although we observed ciliates preying upon Parvilucifera zoospores in microscopic observations of living natural samples in the laboratory, nothing is known about the biological interactions of Parvilucifera parasitoids with non-host organisms present in the plankton community. Indeed, studies on the relationship of Parvilucifera with other trophic levels would be a step forward in understanding energy transfer within marine food webs and in ecological modeling.

In the present study, during the whole bloom period Parvilucifera killed, on average, a low percentage (1-3\%) of the A. minutum planktonic population per day. It was only at the end of the bloom, coinciding with the sharp decrease in A. minutum abundance, that Parvilucifera reached prevalences high enough to cause maximum host mortalities. Similar patterns were observed in field studies of Amoebophrya infection dynamics (Alves-de-Souza et al., 2012; Velo-Suárez et al., 2013). In fact, the host mortalities caused by Amoebophrya infection may be so extreme that the bloom collapses (Chambouvet et al., 2008; Mazzillo et al., 2011). Based on a 5-18\% decrease in the total A. minutum population attributable to Parvilucifera, it can be concluded that parasitism strongly influences bloom dynamics, as it leads to losses that are of the same order of magnitude as those due to other biological factors, such as encystment (Anglès et al., 2012) and grazing (Calbet et al., 2003). However, it is not the only cause of bloom termination; in fact, density-dependent 
disease systems were previously shown to be significantly less likely to cause the extinction of a population (Jaffee et al., 1992). In the case of Parvilucifera parasitoids and dinoflagellates, since their interaction is host-density dependent, the natural course of the infection will lower the density of the host and thus its contact rate with the parasitoid. Fewer host individuals and lower infection rates will lead to the establishment of a population equilibrium between dinoflagellate cells and their parasitoids.

Our study demonstrates that the dynamics of Parvilucifera are well adapted to those of their blooming hosts and therefore that eukaryotic parasitism is an important factor accounting for biological loss during dinoflagellates massive proliferations. In addition, parasitism exhibits both temporal and spatial heterogeneity during high-biomass blooms. Further investigations of the effects of abiotic and biotic factors on the ecology of these parasitoids are needed to understand parasitoid abundance, host interactions, and the link with other trophic levels of the marine food web.

\section{REFERENCES}

Alacid, E., Park, M. G., Turon, M., Petrou, K., and Garcés, E. (2016). A game of Russian roulette for a generalist dinoflagellate parasitoid: host susceptibility is the key to success. Front. Microbiol. 7:769. doi: 10.3389/fmicb.2016.00769

Alacid, E., Reñé, A., and Garcés, E. (2015). New insights into the parasitoid Parvilucifera sinerae life cycle: the development and kinetics of infection of a bloom-forming dinoflagellate host. Protist 166, 677-699. doi: 10.1016/j.protis.2015.09.001

Alves-de-Souza, C., Pecqueur, D., Le Floch, E., Mas, S., Roques, C., Mostajir, B., et al. (2015). Significance of plankton community structure and nutrient availability for the control of dinoflagellate blooms by parasites: a modeling approach. PLoS ONE 10:e0127623. doi: 10.1371/journal.pone.0127623

Alves-de-Souza, C., Varela, D., Iriarte, J. L., González, H. E., and Guillou, L. (2012). Infection dynamics of Amoebophryidae parasitoids on harmful dinoflagellates in a southern Chilean fjord dominated by diatoms. Aquat. Microb. Ecol. 66, 183-197. doi: 10.3354/ame01567

Anderson, D. M. (2009). Approaches to monitoring, control and management of harmful algal blooms (HABs). Ocean Coast. Manag. 52, 342-347. doi: 10.1016/j.ocecoaman.2009.04.006

Anderson, D. M., Alpermann, T. J., Cembella, A. D., Collos, Y., Masseret, E., and Montresor, M. (2012). The globally distributed genus Alexandrium: multifaceted roles in marine ecosystems and impacts on human health. Harmful Algae 14, 10-35. doi: 10.1016/j.hal.2011.10.012

Anglès, S., Garcés, E., Reñé, A., and Sampedro, N. (2012). Life-cycle alternations in Alexandrium minutum natural populations from the NW Mediterranean Sea. Harmful Algae 16, 1-11. doi: 10.1016/j.hal.2011.12.006

Anglès, S., Jordi, A., Garcés, E., Basterretxea, G., and Palanques, A. (2010). Alexandrium minutum resting cyst distribution dynamics in a confined site. Deep Sea Res. Part II 57, 210-221. doi: 10.1016/j.dsr2.2009.09.002

Begon, M., Townsend, C. R., and Harper, J. L. (2005). "The population dynamics of predation," in Ecology: From Individuals to Ecosystems, 4th Edn (Malden, MA: Blackwell Publishers Hoboken), 297-325.

Blanquart, F., Valero, M., Alves-de-Souza, C., Dia, A., Lepelletier, F., Bigeard, E., et al. (2016). Evidence for parasite-mediated selection during short-lasting toxic algal blooms. Proc. R. Soc. B 283:20161870. doi: 10.1098/rspb.2016.1870

Bravo, I., Vila, M., Masó, M., Figueroa, R. I., and Ramilo, I. (2008). Alexandrium catenella and Alexandrium minutum blooms in the Mediterranean Sea: toward the identification of ecological niches. Harmful Algae 7, 515-522. doi: 10.1016/j.hal.2007.11.005

Calbet, A., Vaqué, D., Felipe, J., Vila, M., Sala, M. M., Alcaraz, M., et al. (2003). Relative grazing impact of microzooplankton and mesozooplankton on a

\section{AUTHOR CONTRIBUTIONS}

EA, JC, and EG designed the study. EA, AR, and EG contributed to data acquisition. EA analyzed the results. EA, AR, JC, and EG contributed to interpretation and discussion of the results. EA prepared the manuscript with contributions from all-coauthors.

\section{FUNDING}

This study was supported by the Spanish Ministry of Science and Innovation through the project PARAL (CTM2009-08399) and the project ECOPAR (CSIC Intramural Project) granted to EG.

\section{ACKNOWLEDGMENTS}

We thank N. Sampedro (ICM-CSIC) and Agència Catalana de l'Aigua (ACA, Generalitat de Catalunya), for providing data on toxic phytoplankton monitoring. We also thank C. DomínguezCarrió (ICM-CSIC) for his support during sample collection.

bloom of the toxic dinoflagellate Alexandrium minutum. Mar. Ecol. Prog. Ser. 259, 303-309. doi: 10.3354/meps259303

Chambouvet, A., Berney, C., Romac, S., Audic, S., Maguire, F., de Vargas, C., et al. (2014). Diverse molecular signatures for ribosomally 'active' Perkinsea in marine sediments. BMC Microbiol. 14:110. doi: 10.1186/1471-2180-14-110

Chambouvet, A., Morin, P., Marie, D., and Guillou, L. (2008). Control of toxic marine dinoflagellate blooms by serial parasitic killers. Science 322, 1254-1257. doi: $10.1126 /$ science.1164387

Coats, D. W., Adam, E. J., Gallegos, C. L., and Hedrick, S. (1996). Parasitism of photosynthetic dinoflagellates in a shallow subestuary of Chesapeake Bay, USA. Aquat. Microb. Ecol. 11, 1-9. doi: 10.3354/ame011001

Coats, D. W., and Bockstahler, K. R. (1994). Occurrence of the parasitic dinoflagellate Amoebophrya ceratii in Chesapeake Bay populations of Gymnodinium sanguineum. J. Eukaryotic Microbiol. 41, 586-593. doi: 10.1111/j.1550-7408.1994.tb01520.x

Coats, D. W., and Park, M. G. (2002). Parasitism of photosynthetic dinoflagellates by three strains of Amoebophrya (dinophyta): parasite survival, infectivity, generation time, and host specificity. J. Phycol. 38, 520-528. doi: 10.1046/j.1529-8817.2002.01200.x

de Vargas, C., Audic, S., Henry, N., Decelle, J., Mahé, F., Logares, R., et al. (2015). Eukaryotic plankton diversity in the sunlit ocean. Science 348, 1-11. doi: $10.1126 /$ science.1261605

Dobson, A. P. (1990). "Models for multi-species parasite-host communities," in Parasite Communities: Patterns and Processes, eds G. W. Esch, A. O. Bush and J. M. Aho (London, UK: Chapman and Hall), 261-288.

Edler, L., and Elbrächter, M. (2010). "The Utermöhl method for quantitative phytoplankton analysis," in Microscopic and Molecular Methods for Quantitative Phytoplankton Analysis, eds B. Karlson, C. Cusack, and E. Bresnan (Paris: UNESCO), 13-20.

Egerton, T. A., Morse, R. E., Marshall, H. G., and Mulholland, M. R. (2014). Emergence of algal blooms: the effects of short-term variability in water quality on phytoplankton abundance, diversity, and community composition in a tidal estuary. Microorganisms 2, 33-57. doi: 10.3390/microorganisms2010033

Elton, C. C. (1958). "The reasons for conservation," in The Ecology of Invasions by Animals and Plants, ed C. C. Elton (Dordrecht: Springer), 143-153.

Erard-Le Denn, E., Chrétiennot-Dinet, M. J., and Probert, I. (2000). First report of parasitism on the toxic dinoflagellate Alexandrium minutum Halim. Estuarine Coastal Shelf Sci. 50, 109-113. doi: 10.1006/ecss.1999.0537

Figueroa, R. I., Garcés, E., Massana, R., and Camp, J. (2008). Description, host-specificity, and strain selectivity of the dinoflagellate parasite Parvilucifera sinerae sp nov (Perkinsozoa). Protist 159, 563-578. doi: 10.1016/j.protis.2008.05.003 
Fritz, L., and Nass, M. (1992). Development of the endoparasitic dinoflagellate Amoebophyra ceratii within host dinoflagellate species. J. Phycol. 28, 312-320. doi: 10.1111/j.0022-3646.1992.00312.x

Fritz, L., and Triemer, R. E. (1985). A rapid simple technique utilizing calcofluor white M2R for the visualization of dinoflagellate thecal plates. J. Phycol. 21, 662-664. doi: 10.1111/j.0022-3646.1985.00662.x

Garcés, E., Alacid, E., Bravo, I., Fraga, S., and Figueroa, R. I. (2013a). Parvilucifera sinerae (Alveolata, Myzozoa) is a generalist parasitoid of dinoflagellates. Protist 164, 245-260. doi: 10.1016/j.protis.2012.11.004

Garcés, E., Alacid, E., Reñé, A., Petrou, K., and Simó, R. (2013b). Host-released dimethylsulphide activates the dinoflagellate parasitoid Parvilucifera sinerae. ISME J. 7, 1065-1068. doi: 10.1038/ismej.2012.173

Garcés, E., and Camp, J. (2012). "Habitat changes in the Mediterranean Sea and the consequences for harmful algal blooms formation," in Life in the Mediterranean Sea: A Look at Habitat Changes, ed N. Stambler (Hauppauge, NY: Nova Science Publishers, Inc.), 519-541.

Garcés, E., Bravo, I., Vila, M., Figueroa, R. I., Masó, M., and Sampedro, N. (2004). Relationship between vegetative cells and cyst production during Alexandrium minutum bloom in Arenys de Mar harbour (NW Mediterranean). J. Plankton Res. 26, 637-645. doi: 10.1093/plankt/ fbh065

Garcés, E., Vila, M., Masó, M., and Camp, J. (2003). "Harmful algae blooms in the Mediterranean Sea, the Catalan coast as an example," in The Mediterranean Sea: An Overview of Its Present State and Plans for Future Protection, eds C. Rodriguez-Prieto and G. Pardini (Girona: Servei de Publicacions de la Universitat de Girona), 147-160.

Guillard, R. R. L. (1973). "Methods for microflagellates and nannoplankton," in Handbook of Phycological Methods. Culture Methods and Growth Measurements, ed J. R. Stein. (Cambridge: Cambridge University Press), 69-85.

Guillou, L., Viprey, M., Chambouvet, A., Welsh, R. M., Kirkham, A. R., Massana, R., et al. (2008). Widespread occurrence and genetic diversity of marine parasitoids belonging to Syndiniales (Alveolata). Environ. Microbiol. 10, 3349-3365. doi: 10.1111/j.1462-2920.2008.01731.x

Hallegraeff, G. M., Anderson, D. M., Cembella, A. D., Enevoldsen, H. O., and Commission, I. O. (2003). Manual on Harmful Marine Microalgae. Paris: Unesco.

Hassell, M. (2000). The Spatial and Temporal Dynamics of Host-Parasitoid Interactions. New York, NY: OUP Oxford.

Jaffee, B., Phillips, R., Muldoon, A., and Mangel, M. (1992). Densitydependent host-pathogen dynamics in soil microcosms. Ecology 73, 495-506. doi: $10.2307 / 1940755$

Jephcott, T. G., Alves-de-Souza, C., Gleason, F. H., van Ogtrop, F. F., SimeNgando, T., Karpov, S. A., et al. (2016). Ecological impacts of parasitic chytrids, syndiniales and perkinsids on populations of marine photosynthetic dinoflagellates. Fungal Ecol. 19, 47-58. doi: 10.1016/j.funeco.2015. 03.007

Johansson, M., and Coats, D. W. (2002). Ciliate grazing on the parasite Amoebophrya sp. decreases infection of the red-tide dinoflagellate Akashiwo sanguinea. Aquat. Microbial Ecol. 28, 69-78. doi: 10.3354/ame 028069

Johansson, M., Eiler, A., Tranvik, L., and Bertilsson, S. (2006). Distribution of the dinoflagellate parasite Parvilucifera infectans (Perkinsozoa) along the Swedish coast. Aquat. Microb. Ecol. 43, 289-302. doi: 10.3354/ame043289

Jordi, A., Anglès, S., Garcés, E., Sampedro, N., Reñé, A., and Basterretxea, G. (2015). Role of Competition Processes on Phytoplankton Dynamics Through Advanced Data Assimilation and Adaptive Modeling Granada: ASLO.

Kagami, M., Van Donk, E., de Bruin, A., Rijkeboer, M., and Ibelings, B. W. (2004). Daphnia can protect diatoms from fungal parasitism. Limnol. Oceanogr. 49, 680-685. doi: 10.4319/lo.2004.49.3.0680

Lafferty, K. D., Harvell, C. D., Conrad, J. M., Friedman, C. S., Kent, M. L., Kuris, A. M., et al. (2015). Infectious diseases affect marine fisheries and aquaculture economics. Ann. Rev. Mar. Sci. 7, 471-496. doi: 10.1146/annurev-marine-010814-015646

Leander, B. S., and Hoppenrath, M. (2008). Ultrastructure of a novel tube-forming, intracellular parasite of dinoflagellates: Parvilucifera prorocentri sp nov (Alveolata, Myzozoa). Eur. J. Protistol. 44, 55-70. doi: 10.1016/j.ejop.2007.08.004
Lepelletier, F., Karpov, S. A., Le Panse, S., Bigeard, E., Skovgaard, A., Jeanthon, C., et al. (2014). Parvilucifera rostrata sp. nov. (Perkinsozoa), a novel parasitoid that infects planktonic dinoflagellates. Protist 165, 31-49. doi: $10.1016 /$ j.protis.2013.09.005

Lepère, C., Ostrowski, M., Hartmann, M., Zubkov, M. V., and Scanlan, D. J. (2015). In situ associations between marine photosynthetic picoeukaryotes and potential parasites-a role for fungi? Environ. Microbiol. Rep. 8, 445-451. doi: 10.1111/1758-2229.12339

Llaveria, G., Garcés, E., Ross, O. N., Figueroa, R. I., Sampedro, N., and Berdalet, E. (2010). Small-scale turbulence can reduce parasite infectivity to dinoflagellates. Mar. Ecol. Prog. Ser. 412, 45-56. doi: 10.3354/meps08663

Margalef, R. (1978). Life-forms of phytoplankton as survival alternatives in an unstable environment. Oceanol. Acta 1, 493-509.

Maso, M., and Garcés, E. (2006). Harmful microalgae blooms (HAB); problematic and conditions that induce them. Mar. Pollut. Bull. 53, 620-630. doi: 10.1016/j.marpolbul.2006.08.006

Massana, R., Gobet, A., Audic, S., Bass, D., Bittner, L., Boutte, C., et al. (2015). Marine protist diversity in European coastal waters and sediments as revealed by high-throughput sequencing. Environ. Microbiol. 17, 4035-4049. doi: 10.1111/1462-2920.12955

Mazzillo, F. F., Ryan, J. P., and Silver, M. W. (2011). Parasitism as a biological control agent of dinoflagellate blooms in the California Current System. Harmful Algae 10, 763-773. doi: 10.1016/j.hal.2011.06.009

Montagnes, D. J. S., Chambouvet, A., Guillou, L., and Fenton, A. (2008). Responsibility of microzooplankton and parasite pressure for the demise of toxic dinoflagellate blooms. Aquat. Microb. Ecol. 53, 211-225. doi: $10.3354 / \mathrm{ame} 01245$

Norén, F., Moestrup, O., and Rehnstam-Holm, A. S. (1999). Parvilucifera infectans Norén et Moestrup gen. et sp. nov. (perkinsozoa phylum nov.): a parasitic flagellate capable of killing toxic microalgae. Eur. J. Protistol. 35, 233-254. doi: 10.1016/S0932-4739(99)80001-7

Norén, F., Moestrup, Ö., Rehnstam-Holm, A.-S., and Larsen, J. (2001). "Worldwide occurrence and host specificity of Parvilucifera infectans: a parasitic flagellate capable of killing toxic dinoflagellates," in Ninth International Conference on Harmful Algal Bloom, Hobart, Australia, 2000, eds G. M. Hallegraeff, S. I. Blackburn, C. J. Bolch and R. J. Lewis (Intergovernmental Oceanographic Commission of UNESCO), 481-483.

Park, M. G., Cooney, S. K., Kim, J. S., and Coats, D. W. (2002). Effects of parasitism on diel vertical migration, phototaxis/geotaxis, and swimming speed of the bloom-forming dinoflagellate Akashiwo sanguinea. Aquat. Microb. Ecol. 29, 11-18. doi: 10.3354/ame029011

Park, M. G., Yih, W., and Coats, D. W. (2004). Parasites and phytoplankton, with special emphasis on dinoflagellate infections. J. Eukaryotic Microbiol. 51, 145-155. doi: 10.1111/j.1550-7408.2004.tb00539.x

Råberg, L., Alacid, E., Garces, E., and Figueroa, R. (2014). The potential for arms race and Red Queen coevolution in a protist host-parasite system. Ecol. Evol. 4, 4775-4785. doi: 10.1002/ece3.1314

Salomon, P. S., and Stolte, W. (2010). Predicting the population dynamics in Amoebophrya parasitoids and their dinoflagellate hosts using a mathematical model. Mar. Ecol. Prog. Ser. 419, 1-10. doi: 10.3354/meps08839

Sunda, W. G., Graneli, E., and Gobler, C. J. (2006). Positive feedback and the development and persistence of ecosystem disruptive algal blooms. J. Phycol. 42, 963-974. doi: 10.1111/j.1529-8817.2006.00261.x

Turon, M., Alacid, E., Figueroa, R. I., Reñé, A., Ferrera, I., Bravo, I., et al. (2015). Genetic and phenotypic diversity characterization of natural populations of the parasitoid Parvilucifera sinerae. Aquat. Microb. Ecol. 76, 117-132. doi: 10.3354/ame01771

Van Lenning, K., Vila, M., Masó, M., Garcés, E., Anglès, S., Sampedro, N., et al. (2007). Short-term variations in development of a recurrent toxic Alexandrium minutum-dominated dinoflagellate bloom induced by meteorological conditions. J. Phycol. 43, 892-907. doi: 10.1111/j.1529-8817.2007.00396.x

Velo-Suárez, L., Brosnahan, M. L., Anderson, D. M., and McGillicuddy D. J. Jr. (2013). A quantitative assessment of the role of the parasite Amoebophrya in the termination of Alexandrium fundyense blooms within a small coastal embayment. PLoS ONE 8:e81150. doi: 10.1371/journal.pone.0081150

Vila, M., Camp, J., Garcés, E., Masó, M., and Delgado, M. (2001). High resolution spatio-temporal detection of potentially harmful dinoflagellates in 
confined waters of the NW Mediterranean. J. Plankton Res. 23, 497-514. doi: 10.1093/plankt/23.5.497

Vila, M., Giacobbe, M. G., Masó, M., Gangemi, E., Penna, A., Sampedro, N., et al. (2005). A comparative study on recurrent blooms of Alexandrium minutum in two Mediterranean coastal areas. Harmful Algae 4, 673-695. doi: 10.1016/j.hal.2004.07.006

Zingone, A., and Enevoldsen, H. O. (2000). The diversity of harmful algal blooms: a challenge for science and management. Ocean Coastal Manage. 43, 725-748. doi: 10.1016/S0964-5691(00) 00056-9
Conflict of Interest Statement: The authors declare that the research was conducted in the absence of any commercial or financial relationships that could be construed as a potential conflict of interest.

Copyright (c) 2017 Alacid, Reñé, Camp and Garcés. This is an open-access article distributed under the terms of the Creative Commons Attribution License (CC BY). The use, distribution or reproduction in other forums is permitted, provided the original author(s) or licensor are credited and that the original publication in this journal is cited, in accordance with accepted academic practice. No use, distribution or reproduction is permitted which does not comply with these terms. 